\title{
Cultural Consideration in Online Learning Environment: A Case Discussion of HBMSU Learners, Dubai UAE
}

\author{
A.A.Sathakathulla* \\ Hamdan Bin Mohammed Smart university, Dubai, UAE \\ Nada Essam El harouni \\ Hamdan Bin Mohammed Smart university, Dubai, UAE
}

\begin{abstract}
Universities have been challenged by their environments' changes from having the traditional classes environments to the online environment. Nowadays, students' growing up with the culture of the devices and technologies. Therefore, while having online classes rapidly spread among high-education, the students engaged those classes to have diverse behaviors according to their education and ethnic backgrounds. Because of this, the challenges face the education faculty and the environment designers are to be taking those differences into consideration and develop the educational offers accordingly. As students' perceptions and opinions to their satisfaction level toward the online learning courses have taken the attention of the educational researchers. This paper reviews the previous research which is focusing on the cultures' questions within the online learning. However, none of them have been concentrated on specific variables to be studied. This study addresses the previous research gaps. The aim of the study to help the students of HBMSU university finding answers and solutions for their worries. Specifically, Focusing on the influence of diversified cultures on the students' engagement within the online classes. In order to search for the best effective ways to get the desired outcomes considering the students' differences. Having such study that investigates the students' needs and assesses their factors will give our university the chance to enhance their level of the provided services. Online universities always showing themselves as the best to fit the whole world students. But what is the reality that there are a lot of students are suffering. So, Does the traditional classes' problems that resulted of the cultures variances transferred to the online classes too?The study conducted by developing a web-based survey that reaches a number of students from different majors that existing in our HBMSU University. Perceived their satisfaction level based on multiple factors, and test to which extent their cultures factors have an effect on that.
\end{abstract}

Keywords: Educational \& Ethnic Background, Enhance Online-learning, Student's satisfaction.

DOI: $10.7176 / \mathrm{JEP} / 10-9-13$

Publication date:March $31^{\text {st }} 2019$

\section{Introduction}

In addition to the expansion of using the internet and new technologies, shaping the education into the online environment form is becoming a new paradigm in today's' education. Developing new tools to maintain the demand joining this education method is mandatory. In order to support the learners' success to the maximum, online learning designer and faculty must be taking the human cultures differences into consideration. Those considerations including the ethnic, local, academic and disciplinary cultures variances. The classrooms' social environment is results of the learners' participation extent, and the interaction between the instructional staff, students, and all other factors that may contribute to affect the quality of the online learning environment.

This paper aim is to identify the correlations between the academic, ethnic cultural influences and the level of effectiveness of the online-learning environments. Especially, testing whether those cultural differences influencing the online classes negatively or positively. The study conducted based on the HBMSU learning expectations, needs, experiences and academic success within the context of living both approaches in our university, the traditional (Physical classes) and the Distance (Online classes) experience. This will add to the study results accuracy and will support the study hypothesis.

Starting by mentioning the previous papers results, the literature has supported the need of drawing the attention on the cultural factors in the online education environment, but still, no specific study concentrates on specific cultural factor and investigates the students' perceptions on it. This paper concentrates on having a good background of what problems the HBMSU University's students are facing and need their voices to reach the management of the university. The Survey results will clearly show the factors that the university need to consider, as we know they're passionate to reach the global and expand with a high-quality service to their students.

\section{Literature Review:}

\subsection{Culture definition:}

Defining the "Culture" term is something need a lot of investigation to be understood perfectly. In most past researchers' papers, thy connect the culture term to the ethnic origin and nationality which is mean to have a 
similarity in thoughts, values, and behaviors (HEFCE (2005). The current literature analyzed the term of the culture to be the philosophy, observed traditions, opinions, and the pattern of actions by the individuals and the groups (Branch, 1997). Also, it had been defined as a set of values, beliefs, and attitudes that shared by a group of people and transformed from one generation to the other (Matsumoto, 1996).

The ambiguity of the "Culture" term had been eliminated after the interpretation of one of the papers done by Milani, M. (2007), which is divided the cross-cultural interface into four types of cultures:

* Ethnic culture: The social-psychological features or the nationality background which affect the students' behaviors that may contrast with the instructor's social-psychological background.

* Local Culture: The local settings' aspects which is familiar in each society.

* Disciplinary Culture: The concepts, theories, and norms of a particular discipline.

* Academic Culture: The common academic values, assumptions and the roles of the learners' cultures.

\subsection{Online learning:}

Online learning has been mentioned in many papers as an added value method to the universities competitive advantages. Online learning considered as an innovative approach provided to the learners to deliver a suitabledesigned, interactive, learner-centered, and joining learning environment to anyone, from anyplace and anytime. This done through utilizing the digital resources with the needed learning materials to provide a flexible and open learning environment (B. Khan, 2005).

\subsection{Overview of the problem:}

There are many papers that had discussed the traditional and online learning environment where are many different cultures met in one place or in one virtual room. Considering that it is hard for the instructor to accommodate each one's culture, while the learners are expected to put their own culture aside and temporarily tailor themselves to the instructor's and environment's culture. (Moore, 2006, p. 1) within these expectations, if the instructor's educational values are not matching the student's assumption of the learning design, this will raise the problems. Taking the concept of teaching in an environment that contain dominant values within diverse cultures, is leading to what called "Cultural Hegemony" (Gramsci, 1971). This concept has been studied from previous papers, in trying to formulate a framework for dealing and eliminating the issues behind the multicultural learning environments'. Also, there were papers comparing the factors impacting the effectiveness of the traditional learning with the E-Learning. The factors found are the same in both types of the learning style. (Zhao, Lei, Yan, Lai, and Tan, 2005)

In fact, the online environment is more probably prone to cultural differences problems than the traditional style. Regarding that, the instructor within the E-learning is interacting with students that they physically and socially within their cultures which is unknown to the instructor to be controlled. (Moore, 2006, p. 1).

Online learning system must be build based on the diverse needs and customs of learners, without this, the system can't be effective anymore to get the desired outcome. The designers in the universities should analyze the differences in the cross-cultural communication approaches and the interaction context within each communication form. The different learning styles should be considered efficiently by putting the students desired objectives at the top of priorities (Sanchez, 1998). Most of the studies conclude that the interactive instruction or what called "Learning by Doing" is what can result in a positive impact on the online learning environment and increase the engagement rate of the students. (Watkins, 2005).

\section{Materials and Methods:}

This paper will be based on those previous studies with the extent to find the relationships between the cultural backgrounds of the selected students and their level of satisfaction with the online-based learning environment. Knowing the answers to all the questions related to the research objective is deriving the paper methodology. Starting by stating the study hypothesis, followed by the methodology used and the results out of the data analysis.

\subsection{Hypotheses}

H0: The cultural and educational background of the students does affect their online learning experience.

H1: The cultural and educational background of the students doesn't affect their online learning experience.

\subsection{Research Methodology}

The study method is a quantitative-based method, which is based on a pilot study that conducts a web-based survey in order to test the initial hypothesis and allow an accurate inference. The study used the google form as a method of collecting the data and doing the survey. The targeted participants pooled from the HBMSU University's students that can consider as a study limitation to whom I can reach and provide me with a quick response. The online questionnaire survey made-up of 18 questions dividing into 5 questions as administrative questions, 12 as target questions and 1 as a classification question. The questions formulated as multiple-choice and rating response 
strategy scales. The questionnaires are based into the independent variable to be the online learning environment, and the dependent variables to be the learners' success which characterized by their satisfaction level within the online system design, and their engagement that characterized by their academic and ethnic cultures.

The University population is 3000 learners as they stated, 1320 in the quality major, 660 in health major, 600 in HR major, 240 in accounting major and 180 in the professional diploma stage which the study referred to as "others". In the sampling, the study selected 50 participants (Learners) covering both genders and 5 majors. The study used the stratified probability sampling method to justify the sample size used.
- $\mathrm{QM}=44 \%=22$ learners
* $\mathrm{HM}=22 \%=11$ learners
* HRM $=20 \%=10$ learners
* $\mathrm{ACM}=8 \%=4$ learners
* Others $=6 \%=3$ learners

Then they randomly selected from diverse culture to get diverse opinion and test to which extent the culture values affect the online environment. Participants will receive a link to emails or social media to attend the questionnaire, which is less time-consuming. The resulted data have been analyzed using the SPSS program, in order to get the ANOVA results for testing the proposed hypothesis and support my clues.

\subsection{Data Analysis}

The study analyzed the data based on the convenience of the online learning classes by relating them with nationality-based to represent the ethnic culture and relating them with the major, and the year of study to represent the academic culture.

3.3.1 Convenience of Online classes according to the Ethnic Group

Table 3.3.1: Descriptive data according to the ethnic group: (SPSS, self-created)

\begin{tabular}{|c|c|c|c|c|c|c|c|c|}
\hline & & & & Descrip & tive & & & \\
\hline Online Class Conven & ienc & & & & & & & \\
\hline & & & Std. & Std. & $\begin{array}{r}95 \% \text { Confiden } \\
\mathrm{Me}\end{array}$ & $\begin{array}{l}\text { ce Interval for } \\
\text { an }\end{array}$ & & \\
\hline & $\mathrm{N}$ & Mean & Deviation & Error & Lower Bound & Upper Bound & Minimum & Maximum \\
\hline $\mathrm{GCC}$ & 23 & 1.52 & 1.123 & .234 & 1.04 & 2.01 & 0 & 3 \\
\hline $\begin{array}{ll}\text { Asian } & \text { Arab } \\
\text { Countries } & \\
\end{array}$ & 19 & 1.84 & 1.119 & .257 & 1.30 & 2.38 & 0 & 4 \\
\hline $\begin{array}{ll}\text { African } & \text { Arab } \\
\text { Countries } & \end{array}$ & 7 & 2.29 & .951 & .360 & 1.41 & 3.17 & 1 & 4 \\
\hline Western Countries & 1 & 1.00 & & & & & 1 & 1 \\
\hline Total & 50 & 1.74 & 1.103 & .156 & 1.43 & 2.05 & 0 & 4 \\
\hline
\end{tabular}

The above 3.3.1 Table shows the number of students from each ethnic group. A number of students from African Arab mean than others as they have a higher number of participants in this study.

Table 3.3.2: ANOVA test for the data: (SPSS, Self-created)

\begin{tabular}{|l|r|r|r|r|r|}
\hline \multicolumn{7}{|c|}{ ANOVA } \\
\hline Online Class Convenience & \multicolumn{1}{|c|}{ F } & p-value. \\
\hline & Sum of Squares & df & Mean Square & 1.081 & .367 \\
\hline Between Groups & 3.926 & 3 & 1.309 & & \\
\hline Within Groups & 55.694 & 46 & 1.211 & & \\
\hline Total & 59.620 & 49 & & & \\
\hline
\end{tabular}

According to the ANOVA test: there is a significant relationship between ethnic groups and the convenience of online classes. Students from North African countries prefer the online classes the most among all the ethnic groups. This is followed by Arab Asian countries and then GCC and finally, students from western countries have the least interest in online classes. 


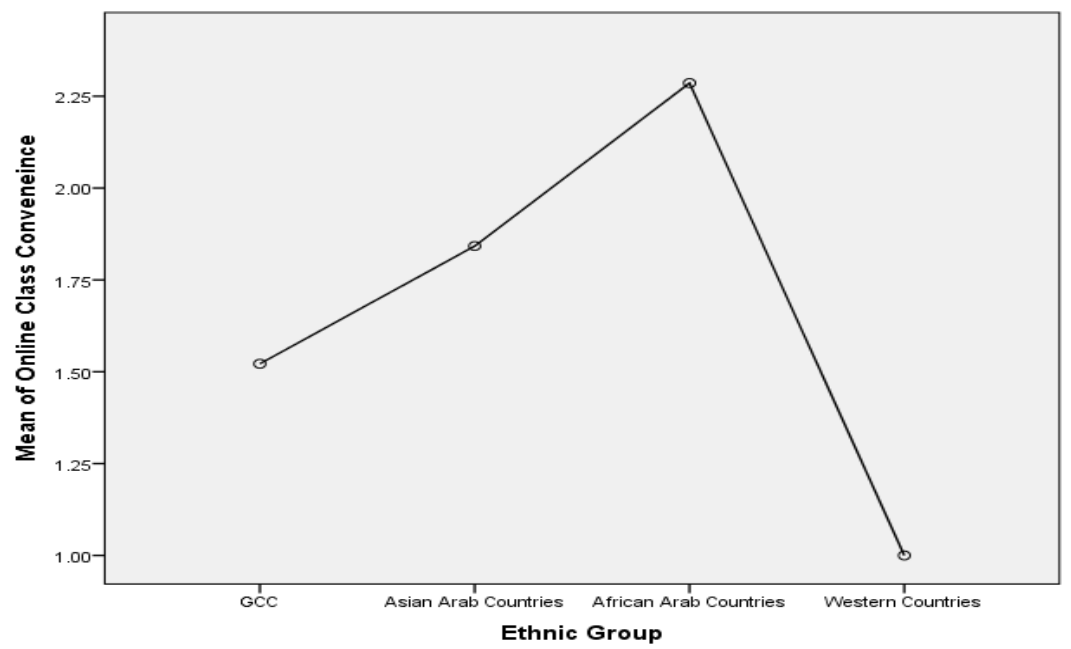

Figure 3.3.1: Online learning convenience based on the major: (SPSS, Self-created) 3.3.2 Convenience of Online classes according to the major

Table 3.3.3: Descriptive data according to the major: (SPSS, self-created)

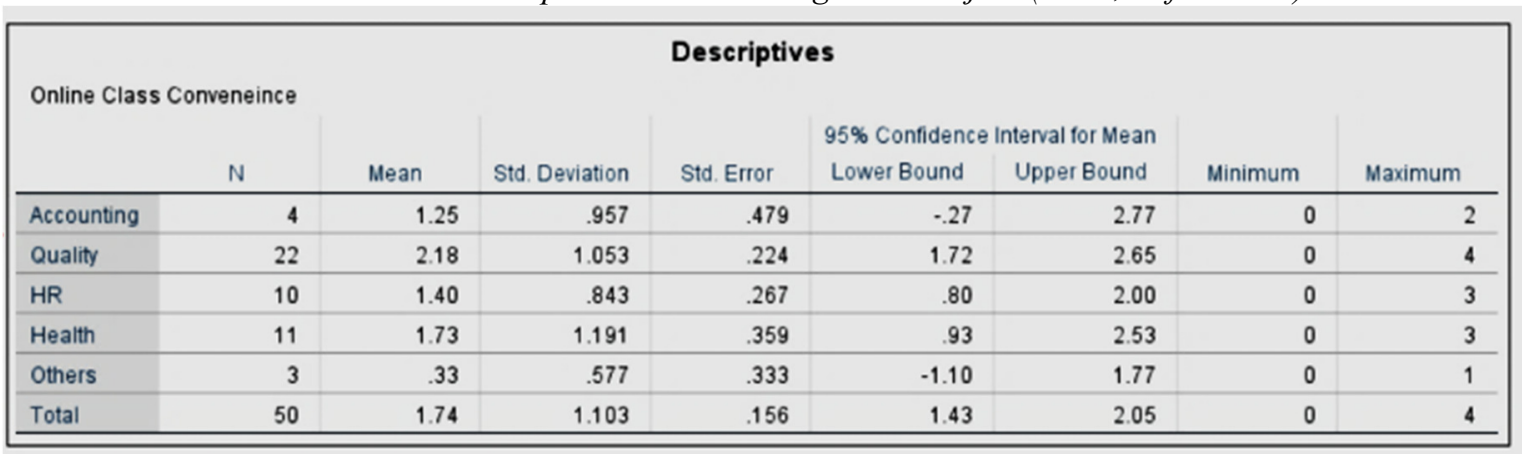

Table 3.1 shows the mean of each one of the study majors who participated in the study. The highest mean belongs to the students from Quality Major as they were the highest number of participants.

Table 3.3.4: ANOVA test for the data: (SPSS, Self-created)

\begin{tabular}{|l|r|r|r|r|r|}
\hline \multicolumn{7}{|c|}{ ANOVA } \\
\hline Online Class Convenience & \multicolumn{1}{|c|}{ F } & P-value. \\
\hline & Sum of Squares & DF & Mean Square & F & .939 \\
\hline Between Groups & 12.349 & 4 & 3.087 & & \\
\hline Within Groups & 47.271 & 45 & 1.050 & & \\
\hline Total & 59.620 & 49 & & & \\
\hline
\end{tabular}

According to the ANOVA Table 3.3.2, that shows that there is a significant relationship between the study major and convenience of online classes. Students from quality major prefer the online classes more than other majors, then students from health major followed by HR and accounting. Students from other groups don't prefer online classes compared to the other four majors. 


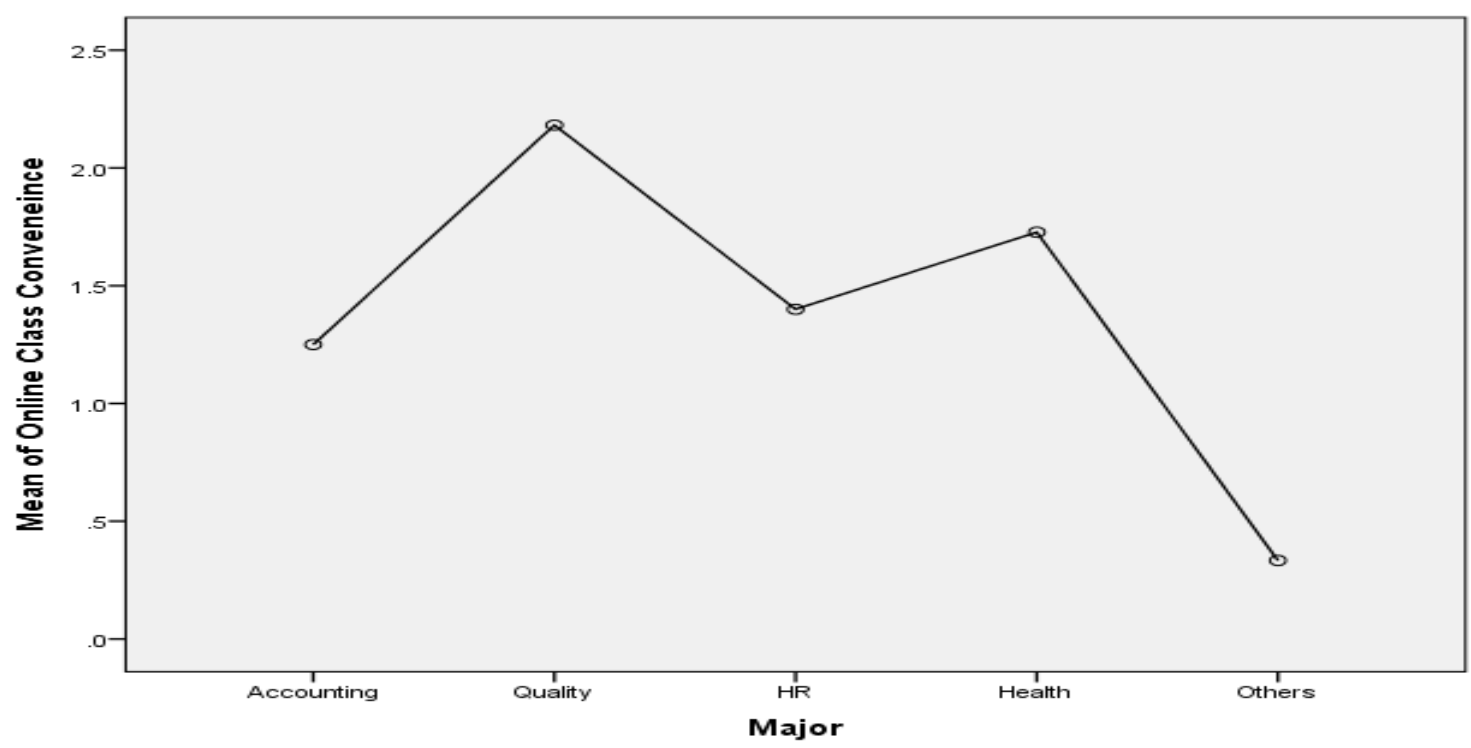

Figure 3.3.2: Online learning convenience based on the major: (SPSS, Self-created) 3.3.3 Convenience of Online classes according to the year of study

Table 3.3.5: Descriptive data according to the year of study: (SPSS, self-created)

\begin{tabular}{|c|c|c|c|c|c|c|c|c|}
\hline \multicolumn{9}{|c|}{ Descriptive } \\
\hline \multicolumn{9}{|c|}{ Online Class Convenience } \\
\hline & \multirow[b]{2}{*}{$\mathrm{N}$} & \multirow[b]{2}{*}{ Mean } & \multirow[b]{2}{*}{$\begin{array}{c}\text { Std. } \\
\text { Deviation }\end{array}$} & \multirow[b]{2}{*}{ Std. Error } & \multicolumn{2}{|c|}{$\begin{array}{l}95 \% \text { Confidence } \\
\text { Interval for Mean }\end{array}$} & \multirow[b]{2}{*}{ Minimum } & \multirow[b]{2}{*}{ Maximum } \\
\hline & & & & & $\begin{array}{l}\text { Lower } \\
\text { Bound }\end{array}$ & $\begin{array}{l}\text { Upper } \\
\text { Bound }\end{array}$ & & \\
\hline First Year & 2 & .00 & .000 & .000 & .00 & .00 & 0 & 0 \\
\hline Second Year & 11 & 2.45 & 1.293 & .390 & 1.59 & 3.32 & 0 & 4 \\
\hline Third Year & 14 & 1.93 & .730 & .195 & 1.51 & 2.35 & 1 & 3 \\
\hline Fourth Year & 18 & 1.61 & .979 & .231 & 1.12 & 2.10 & 0 & 3 \\
\hline $\begin{array}{l}\text { More than } 4 \\
\text { Years }\end{array}$ & 5 & .80 & .837 & .374 & -.24 & 1.84 & 0 & 2 \\
\hline Total & 50 & 1.74 & 1.103 & .156 & 1.43 & 2.05 & 0 & 4 \\
\hline
\end{tabular}

The above 3.3.5 table shows the number of student from different years at the university. The highest convenience rate among students belongs to the students from the second year. This is followed by students from the third and fourth year. The least mean is for a student from the first year.

Table 3.3.6: ANOVA test for the data: (SPSS, Self-created)

\begin{tabular}{|c|c|c|c|c|c|}
\hline \multicolumn{6}{|c|}{ ANOVA } \\
\hline \multicolumn{6}{|c|}{ Online Class Convenience } \\
\hline & Sum of Squares & df & Mean Square & $\mathrm{F}$ & P-value. \\
\hline Between Groups & 16.886 & 4 & 4.222 & 4.445 & .09 \\
\hline Within Groups & 42.734 & 45 & .950 & & \\
\hline Total & 59.620 & 49 & & & \\
\hline
\end{tabular}

ANOVA Test Table 3.3.6: there is a significant relationship between the year of study and the convenience of online classes. The student from the second year is the highest, I think this is based on their excitement for the online classes. Then the level of convenience drops in the third and fourth year due to the repetitive experience of online classes. 


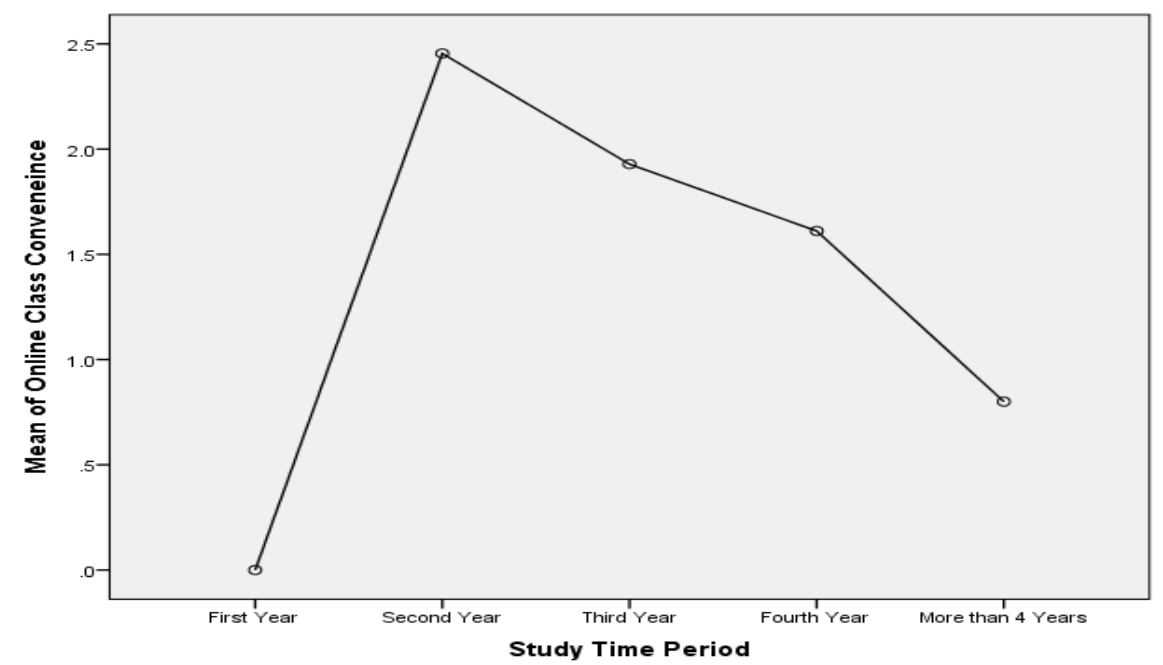

Figure 3.3.3: Online learning convenience based on the year of study: (SPSS, Self-created)

\subsection{Data results}

3.4.1 Factors that affect the students' engagement represented by Pie-Charts

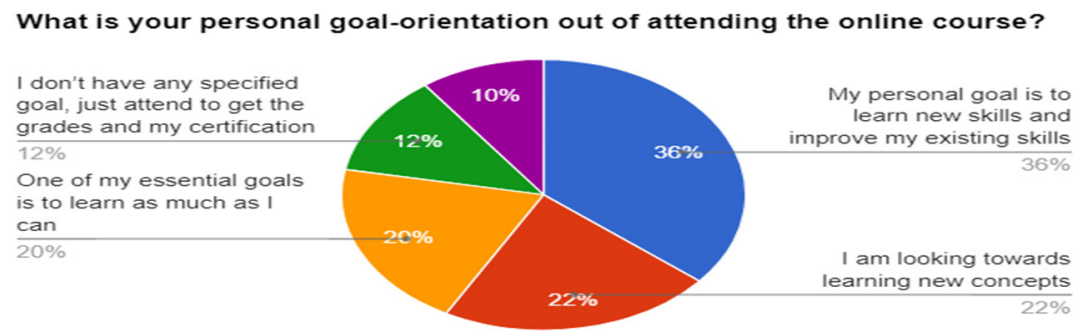

Figure 3.4.1: Personal goal-oriented out of online-class attending:

The figure shows that most of the students attending to learn new skills and improve their existing skills, which is mean that the university should consider this need while designing their class activities. Increasing the students' engagement within the class is related to this factor.

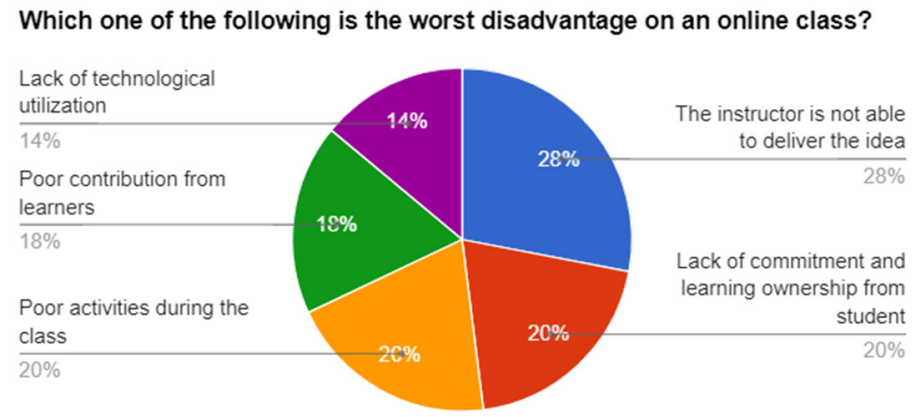

Figure 3.4.2: The Worst disadvantage on an online class

This figure clarifies the disadvantage of the online class from the students' perceptions. Its state that the ability of the instructor to deliver the ideas for diverse people cultures is affecting their level of engagement, which needs to be in consideration while selecting the instructors to teach the courses. 


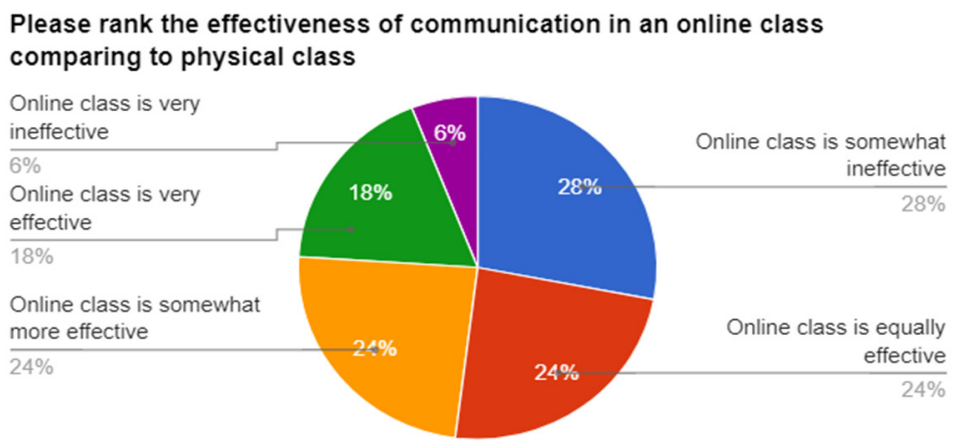

Figure 3.4.3: Compare the effectiveness of communication

In this figure, the students state that the physical classes are more effective regarding the communication tools and abilities. This show that the techniques of formulating the digital tools and the instructors' ways of communication with the students need to be enhanced.

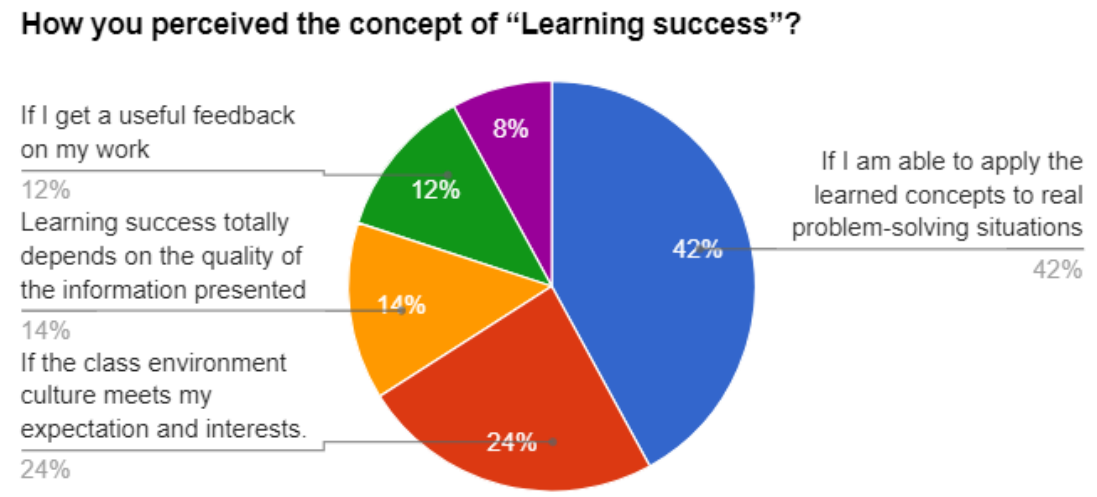

Figure 3.4.4: How the student perceived the learning success

This figure demonstrates that the students' engagements are linked to learning the ability to apply the concepts to real-life situations, in another word "Learning by Doing".

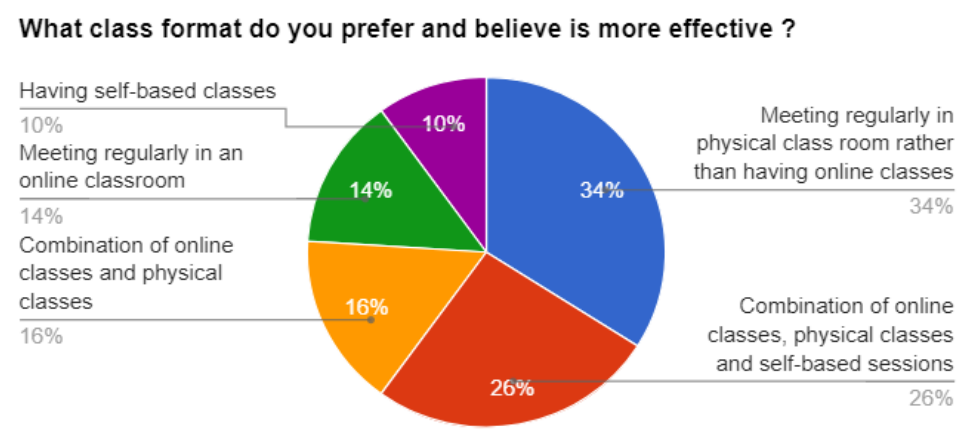

Figure 3.4.5: Conclusion of which types of learning more effective

This figure represents that the university still didn't achieve the level of the quality that makes the students like the online classes more than the Physical-classes regarding the factors which are presented above.

\subsection{Data Inference}

As the study and the data analysis by the SPSS prove the acceptance of the proposed hypothesis to be true. Regarding the p-value of the data showed by the INOVA test, it clear that all value higher than the significance level of (0.05). Analyzing the convenience level according to the major is support the educational background to have an effect on the learners' online-learning environment. Also, analyzing the convenience level based on the ethnic group is clearly shows the impact of the effect of the different culture on the online learning environment. At the end, the results of the questionnaires Pie-charts also demonstrate the factors that affect the students' engagements and participation within the online class. Considering all those factors, the study conclude that the cultural and educational background of the students does affect their online learning experience which is based on meeting their needs and expectation, the extent of using the learning by doing techniques, and to let them learn somethings adding to their skills and abilities to deal with real-life cases. 


\section{Conclusion}

The academic and ethnic cultural differences' in the online-learning environment should be highlighted to the priority of the study. The result and the literature of the study have been evaluated that there is a significant relationship between the learners' educational and ethnic cultures and the online environment success. the cultural differences factor does have a direct impact on participants engagement and satisfaction with the university. The study is providing a suitable background of the problem that can benefit the learners and the university to understand the best way to enhance their quality of learning. HBMSU can stand at the top of the global ladder if start considering their customers' voice and meeting their needs and expectation. Internal satisfaction will lead to the external satisfaction too. Also, the study is a good evaluation for the students themselves, they can specify their barriers and start working on it to be solved. They can't bridge the gap without an action from both sides.

\section{References}

Badrul H. Khan, Managing E-learning Strategies: Design, Delivery, Implementation and Evaluation, Information science Publishing, United States of America, 2005.

Branch, R. M. (1997) Educational technology frameworks that facilitate culturally pluralistic instruction, Educational Technology, 37(2), pp 38-41.

Gramsci, A. (1971). Selections from the prison notebooks. London: Lawrence and Wishart.

HEFCE (2005) UK e-learning strategy, [online],

http://www.heacademy.ac.uk/e-learningimplementation.htm

Matsumoto, D. (1996) Culture and psychology, New York, Brooks Cole.

Milani, M. (2007) "Cultural Differences in Academic Online Courses Quality Perception and Assessment", EdMedia Conference 2007, Vancouver.

Moore, M. (2006). Editorial. The American Journal of Distance Education. 20(1), 1-5.

Sanchez, I., and Gunawardena, Understanding and supporting the culturally diverse distance learner, Atwood Publishing Madison, 1998

Watkins, R. (2005). Developing interactive e-learning activities. Performance Improvement, 44, 5-7.

Zhao, Y., Lei, J., Yan, B., Lai, C., \& Tan, H. S. (2005) What makes the difference? A practical analysis of research on the effectiveness of distance education. Teachers College Record, 107(8), 1836-1884. 